\title{
Del saber al ser: una \\ aproximación a la \\ pintura contemporánea
}

\section{Artículo de investigación}

Javier Garcerá

Universidad de Málaga (España)

javiergarcera@gmail.com

Recibido: 15 de mayo de 2017

Aprobado: 20 de agosto de 2017

Cómo citar este artículo: Garcerá, Javier. (2018)

Del saber al ser: una aproximación a la pintura contemporánea. Calle14: revista de investigación en el campo del arte 13 (23) pp. 134-147. DOI: https://doi. org/10.14483/21450706.12994

Agradecimientos. Este artículo recoge resultados de la investigación "Transculturalidad, mestizaje y mundialización: Aproximaciones interdisciplinares teórico prácticas al arte contemporáneo, Oriente - Occidente", financiada por el Ministerio de Economía y Competitividad. 



\title{
Resumen
}

En el contexto del arte contemporáneo, cada vez es más frecuente encontrar artistas de las generaciones más jóvenes que elaboran sus obras desde un lenguaje construido a través de un esmerado dominio de la técnica y el oficio y que reivindican el hacer como modo de recuperar una significación a través de la atracción de la sensualidad de la materia. Partiendo de tres pintores contemporáneos de procedencia oriental y reflexionando en torno a las influencias que desde los años cuarenta del siglo pasado las filosofías orientales han ejercido en el arte realizado en Occidente, se plantea una reflexión sobre las condiciones que dichas obras imponen en el ver y, por lo tanto, en la recepción de las intenciones poéticas del autor por parte del espectador. Se trata así de plantear un posible acercamiento a la pintura contemporánea desde unas claves de lectura íntimamente relacionadas con el saber del proceso, con la materia, con el tiempo y con la demora.

\section{Palabras claves}

Pintura contemporánea, contemplación, tiempo, ritmo, demora.

From knowledge to being: an approach to contemporary painting

\begin{abstract}
In the context of contemporary art, it is increasingly common to find artists of younger generations creating their artwork from a language built upon a painstaking command of skill and technique, and who vindicate the making as a means to win back new meanings through the attraction to the sensuality of materials. After discussing three Oriental contemporary painters and the influence that Eastern schools of philosophy had on Western art after the 1940s, this article analyses the conditions which works of art impose on the act of seeing and, therefore, on the reception of the artist's poetic views by the observer. It is thus possible to draw up a certain approach to contemporary painting which stems from a set of guidelines closely connected with the understanding of processes, with materials, with time, with the act of lingering.
\end{abstract}

\section{Keywords}

Contemporary painting, contemplation, time, rhythm, lingering.

\section{De la connaissance à l'être : une approche à la peinture contemporaine}

\section{Résumé}

Dans le contexte de l'art contemporain, il est de plus en plus courant de trouver des artistes de jeunes générations qui créent leur œuvre à partir d'une langue élaborée avec compétence et technique, et qui revendiquent la fabrication comme un moyen de reconquérir de nouvelles significations à travers la sensualité des matériaux. Après une discussion sur trois peintres orientaux contemporains et l'influence des écoles de philosophie orientales sur l'art occidental après les années 1940, cet article analyse les conditions que les œuvres imposent à l'acte de voir et donc à la réception des visions poétiques de l'artiste par l'observateur. Il est ainsi possible d'élaborer une certaine approche à la peinture contemporaine qui découle d'un ensemble de lignes directrices étroitement liées à la compréhension des processus, aux matériaux, au temps, à l'acte de s'attarder.

\section{Mots clés}

Peinture contemporaine, contemplation, temps, rythme, persistance. 


\section{Resumo}

No contexto da arte contemporânea, é cada vez mais comum encontrar artistas de gerações mais jovens criando suas obras de arte a partir de uma linguagem baseada em um minucioso comando de habilidade e técnica e que reivindicam a criação como meio para recuperar novos significados através da atração de a sensualidade dos materiais. Depois de discutir três pintores contemporâneos orientais e a influência que as escolas orientais da filosofia tiveram na arte ocidental após a década de 1940, este artigo analisa as condições que as obras de arte impõem no ato de ver e, portanto, na recepção dos pontos de vista poéticos do artista o observador. Assim, é possível elaborar uma determinada abordagem da pintura contemporânea que decorre de um conjunto de diretrizes intimamente relacionadas com a compreensão dos processos, com os materiais, com o tempo, com o ato de demorar.

\section{Palavras-chave}

Pintura contemporânea, contemplação, tempo, ritmo, persistente

\section{Iachaspa pim kangaspa: kaiaira sug llunchiska sug iura pangapi}

\section{Maillallachiska:}

Kai kilkaska pangapi kai punchakunapi,m kawarimi kai ruraikuna kai llunchikunapi ruraska musukuna i iapa suma iachaikuskakuna kai tsabajukuna chasa ruraspaka iuiarinkunami ikuti iuiarispa sug antiwakunamandata sumaglla kaskamanda. Kai llunchigkuna kami kimsa taita maichukuna kaskakuna sus indi iuarmanda kaskamanda i chasa kai watamanda chusku atun watakunamanda i siglukunamandata i sug luar suti occidintimanda chasami iuiarispa kai ka suma kawaspa, chasa kai kilkaskamanda suma virsiami rura kai rurag, chasa ruraspa mas kaiaiarimi kai Ilunchiikunama i kawachispa kai punchakunapi chasami kai ruraikuna iapa suma chaiami kawari ruraska, i maitukupas unariarispa.

\section{Rimangapa Ministidukuna:}

Iuchiska su iura pangapi kai punchakuna, kawachii, imasa urra, imasami chapsirii, maituku unai. 


\section{Contexto}

Si desde la década de los 60 y 70 hemos presenciado en buena parte del arte contemporáneo una creciente tendencia a la desmaterialización del objeto artístico, hay que destacar que en la década actual están apareciendo cada vez más artistas que viven intensamente el proceso de elaboración de la obra, que elaboran sus discursos desde un lenguaje construido sobre un esmerado dominio de la técnica y la manualidad y que, frente a aquellos procesos de minimización e incluso de eliminación del objeto artístico, reivindican el hacer y el oficio como modo de recuperar la atracción de la sensualidad de la materia.

Va a servirnos como ejemplo y punto de partida de este artículo la obra de unos artistas de procedencia oriental que, utilizando un cuidado y minucioso lenguaje, desafían los límites de la representación pictórica a través de distintas estrategias formales que buscan todas ellas una cierta negación de la imagen y una obstaculización de la mirada y que, huyendo de toda solución denotativa, dan una oportunidad a la construcción de relaciones que van más allá de las limitaciones del discurso racional, proponiendo una reflexión frente a las posibilidades de los códigos pictóricos contemporáneos y el proceso del ver.

Me estoy refiriendo a Qiu Shishua (China, 1940)1, que genera una ambigüedad formal a través del empleo de un bajo contraste tan tenue que exige de un prolongado ejercicio de percepción para que sus imágenes comiencen a aparecer (Figs. 1 y 5); a Fu Xiaotong (China, 1976), que consigue construir una enigmática sugerencia del paisaje mediante un meticuloso calado del papel que conforma complejas tramas de puntos (Figs. 2 y 2a.); y a Ohba Daisuke (Japón, 1981) que propone una imagen también huidiza a través del diálogo entre los distintos acabados de su propia materia pictórica (Figs. 3 y 4). Es interesante destacar que estos tres artistas están interesados en ofrecer un tipo de obra que suscita una escucha de la materia en torno a conceptos como contemplación, meditación, vacío, silencio, etc., propios de su cultura oriental, pero que desde los años cuarenta del pasado siglo sirvieron también de inspiración a artistas

1 Aunque Qiu Shishua pertenece a una generación anterior a los otros artistas mencionados se incluye aquí, valorando la calidad de su obra y entendiendo que Esta ha servido de referente a generaciones más jóvenes de artistas. como Ad Reinhardt, Marc Tobey, Franz Kline, Philip Guston, Georgia O'Keeffe o Lee Mullican, entre otros².

Muchos han sido los intentos de comprender las filosofías orientales por parte de los artistas occidentales tras la llegada a Estados Unidos de los primeros maestros hinduistas y budistas. Desde que a principios de 1950 Daisetz Teitaro Suzuki impartiera sus enseñanzas en centros de importante influencia cultural en el contexto americano del momento (como fue por ejemplo la Universidad de Columbia), y a las que asistían artistas de la talla de John Cage, o desde que a finales de esa misma década Shunryu Suzuki se instalara en San Francisco para impartir también enseñanzas sobre budismo zen y más tarde publicara su legendario libro Zen Mind, Beginner's Mind, la preocupación de muchos artistas por el espacio que comparte la mente que crea, la mente que percibe y la mente que medita ha estado y sigue estando presente.

Si en el mundo moderno la relación entre el arte y la espiritualidad ha sido complicada y muchas veces inexistente, la influencia en el arte contemporáneo de estas filosofías, y en concreto del budismo, ha sido y sigue siendo relevante. Un buen ejemplo de ello es el proyecto titulado Awake: Art, Buddishm, and the Dimensions of Consciousness, que consistió en un programa bienal iniciado en la primavera de 2001 de encuentros trimestrales centrados en el estudio del budismo y su relación con el arte contemporáneo, y en el que participaron artistas como Laurie Anderson, Bill Viola, Marina Abramovic, Ann Hamilton, Zhang Huan, Michael Rotondi, Sanford Biggers y Ernesto Pujol, así como representantes de los principales museos e instituciones americanas. En tales encuentros se estudió y demostró que siguen existiendo hoy artistas que, nutriéndose en este caso del budismo, son capaces de superar los límites de cualquier doctrina para enriquecer su vida y su práctica artística desde una perspectiva que les permite acceder a un estado mental de apertura y consciencia expandida, a una experiencia del tiempo

\footnotetext{
2 Para más información sobre dichos artistas, pueden consultar se las siguientes páginas web: http://www.galerie-karsten-greve.com/en/qiu_shihua/works/ paintings.

https://www.google.es/search?q=Qiu+Shishua\&oq=Qiu+ Shishua\&aqs=chrome..69i57.1042j0j7\&ssourceid=chrome\&cie= UTF-8, https://www.artsy.net/artist/fu-xiaotong, http://chambersfineart.com/artists/Fu_Xiaotong/FXT-720000Pricks. shtml.

http://www.scaithebathhouse.com/en/artists/daisuke_ohba/, http://www.scaithebathhouse.com/en/artists/daisuke_ohba/selected/
} 


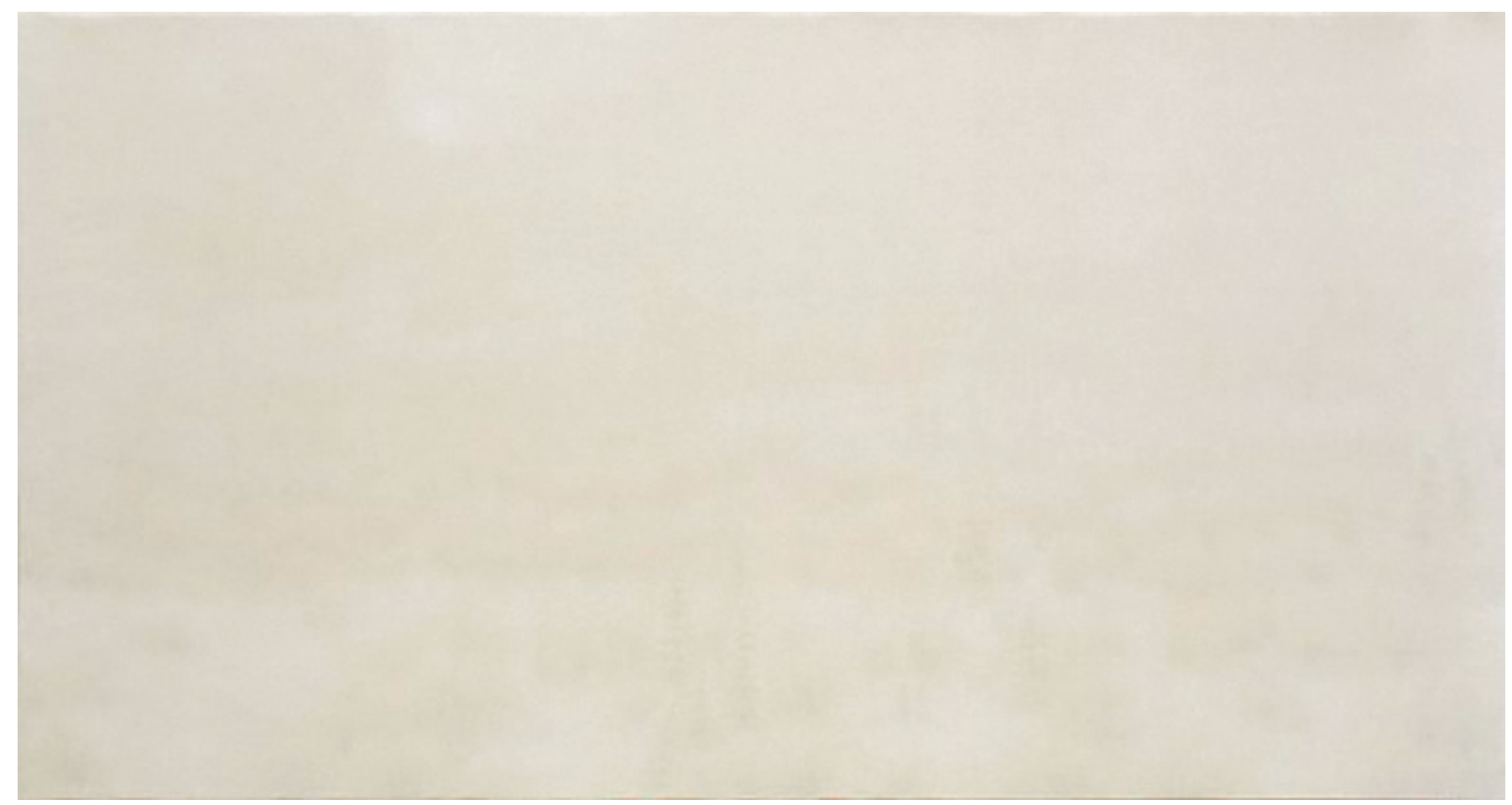

Fig. 1. Qiu Shishua, Sin título (2013), 127 × 240 cm., óleo sobre tela.

y del espacio en el hacer que conforma, de la misma manera, una intensificación en el ver del espectador en el momento de la fruición estética.

\section{Del saber y del ser}

Los gurús o maestros de yoga y meditación afirman que, cuando se consigue a través de la práctica despojar nuestra percepción del mundo de las representaciones que construye nuestra mente y que están basadas en la memoria del pasado y la imaginación del futuro; cuando conseguimos ver, dicen ellos, la realidad como la realidad es, lo único que queda es una cierta forma de presente: un presente que no se interpreta como punto de articulación de un pasado y un futuro, sino como un estado que permanece autónomo, siempre presente, y al que denominan presencia. Una presencia que no sería más que el estado de un sujeto instruido que sabe diferenciar entre la realidad y su representación, entre los objetos y la elaboración mental que construimos a partir de ellos, un estado difícil de entender teóricamente desde el punto de vista de nuestra cultura occidental y que aparecería, según los maestros, cuando, a través de la práctica, somos capaces de alejarnos de la forma temporal que elabora la consciencia cognoscitiva, base fundamental de nuestro modo de conocimiento.
Desde su punto de vista, la realidad, que no su representación, posee otra dimensión, a la que se accede únicamente desde una presencia que desvela su naturaleza más esencial, y se refiere a lo que en los textos budistas chinos y japoneses se denomina el rostro originario, o a lo que los hindúes llaman el testigo, un estado ligado a otra consciencia que desplaza a esa consciencia cognoscitiva que acabamos de mencionar y que disuelve la intencionalidad propia de un sujeto deseante, para entregarse a un todo presente que conlleva la superación de la dualidad sujeto-objeto tan arraigada a nuestra cultura occidental, permitiendo así el acceso a un conocimiento de lo que está más allá de lo particular y que definen como la verdadera consciencia pura.

La duda sobre la existencia de las cosas que nos rodean y la sospecha de que nuestra experiencia vital humana está basada en algún tipo de error o ilusión es un discurso que ha recorrido la historia de nuestro pensamiento occidental y ha tintado nuestra relación con el mundo. El lamento frente al "flujo eterno de las cosas" a "lo que deviene siempre y nunca es" o la oposición entre "lo conocido como mera apariencia y la cosa en sí" serían ejemplos que dan cuenta de ello. Pero también en el contexto de la cultura oriental esta desconfianza en los modos de conocer está presente. Los Vedas y Puranas se refieren a ello cuando hablan de máyá: un hechizo provocado, una apariencia inestable, irreal en sí 


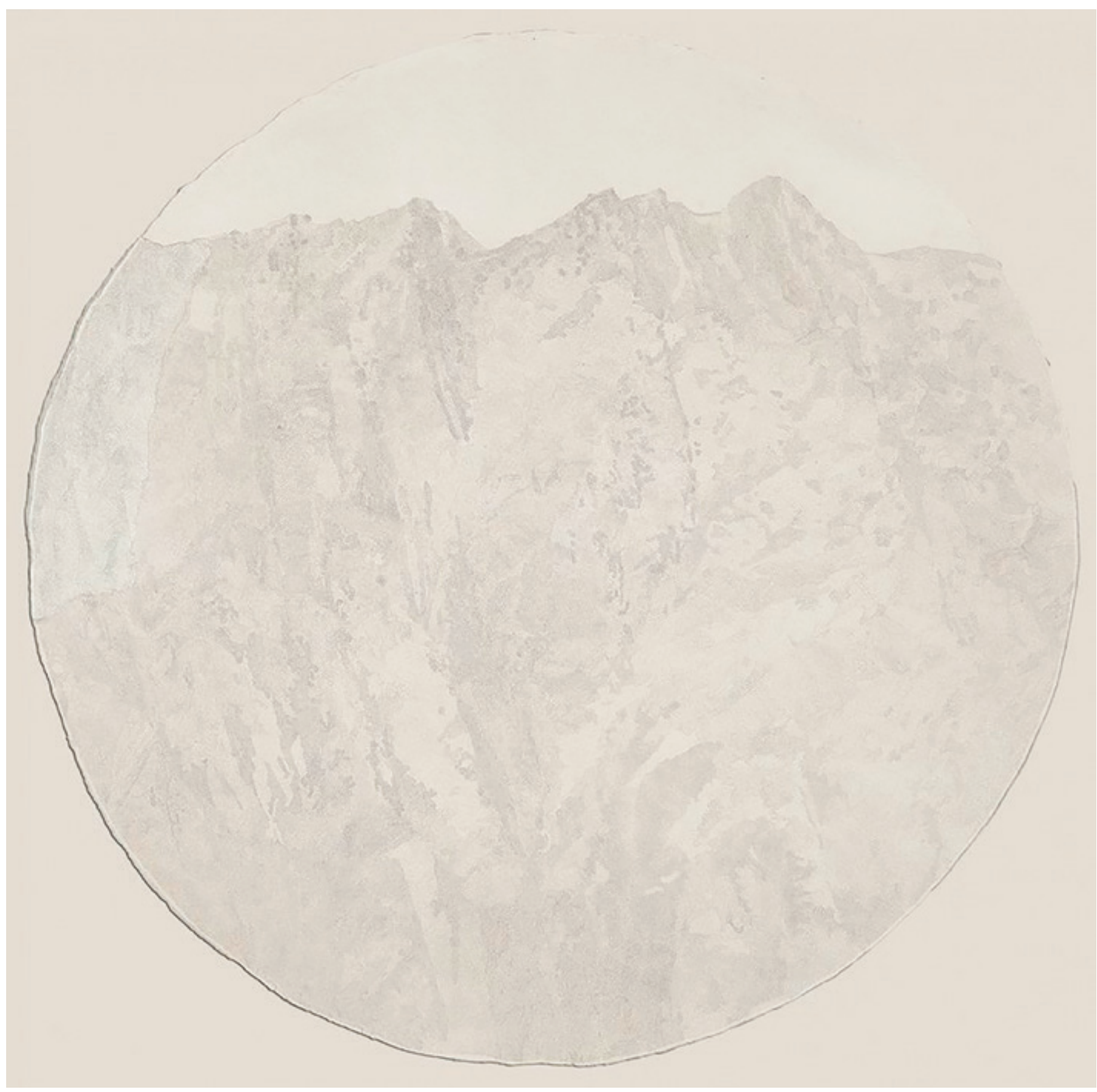

Fig. 2. Fu Xiaotong, 1.152.000 Pinpricks (2013), 143 × $141 \mathrm{~cm}$., papel hecho a mano. 


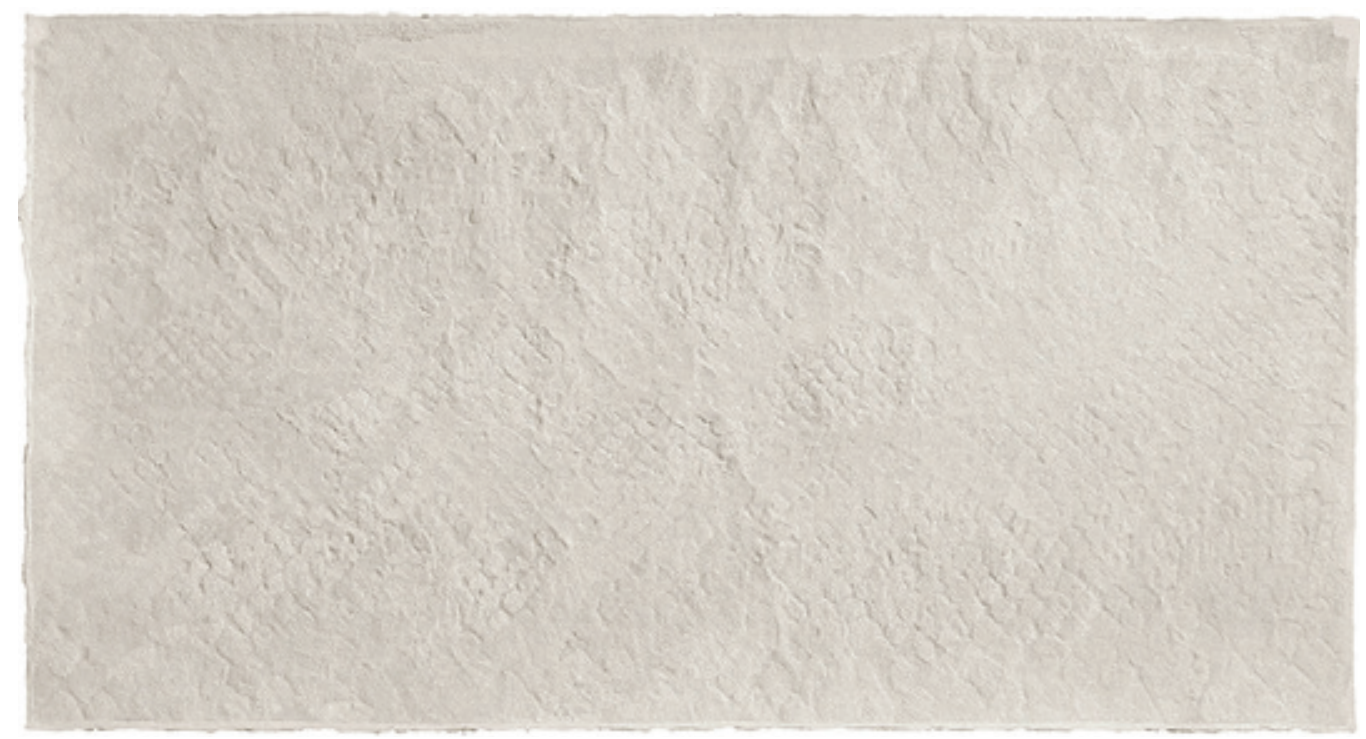

Fig. 2ª Xiaotong, 1.152.000 Pinpricks (2013), $143 \times 141 \mathrm{~cm}$., papel hecho a mano. Detalle.

misma y comparable a la ilusión óptica y al sueño que, como un velo, envuelve la consciencia humana para así alejarnos de una percepción certera del mundo³.

Sin embargo, a la vez, y esto es quizá su gran aportación, desde Oriente se han ofrecido caminos para liberarse de esa distorsión de nuestra percepción habitual del mundo que permiten situar al sujeto en un estado en el que el devenir del tiempo puede ser controlado, e incluso suspendido, a través del cese de la actividad de la consciencia cognoscitiva. El nirvana de los budistas o el moksha de los hindúes no es más que una liberación de la capacidad ilusoria de esa consciencia cognoscitiva que obliga al sujeto a creer en una realidad que se desarrolla y se desvanece en el tiempo.

A través de esos caminos, los maestros o gurús son capaces de escapar del tiempo y ser "testigo" desde y

3 Respecto a la desconfianza ante la realidad que nos rodea, es interesante señalar que los cuatro principales sistemas o escuelas filosóficas budistas (Vaibhashika, Sautrantika, Chittamatra, Madhyamika) ofrecen un panorama general de las diversas explicaciones acerca de la naturaleza última de la realidad descrita por el Buda. El entendimiento de la realidad consiste en lograr la visión correcta de la vacuidad, y dichas escuelas razonan paulatinamente una sucesión de refutaciones que conducen a dicha vacuidad: se empieza refutando la existencia inherente del yo, posteriormente la de los fenómenos, seguida de la de la mente y, por último, la del vacío en sí mismo, asegurando que no hay posibilidad de creer en una existencia inherente o verdadera ni siquiera nominalmente. en la consciencia pura, descubriendo que, a través de la atención al instante, se cruza la puerta que permite el paso a lo atemporal; que, en quietud, el individuo se libera de los lazos temporales y de la mano de la presencia, permanece en la estabilidad del instante. A través del Vedánta Advaita, el sujeto se sumerge en una realidad atemporal que no requiere para mantenerse ni de un antes ni de un después; es decir, en un estado en el que desaparecen las categorías propias de la temporalidad del sujeto, consiguiendo así que el presente fugaz se nos muestre como un presente absoluto que no se mezcla ni con lo que sucedió ni con el devenir y que, según los maestros, desvela la eternidad que se aloja en el fondo de cada momento: "Una gota de agua sobre una hoja es infinita. Esa gota de agua en esta hoja, ahora, en este instante", dirá Chantal Maillard (2008: 32); una eternidad entendida como una totalidad del tiempo que se aprehende en un instante infinitamente corto de iluminación alojado en una consciencia pura que no comprende de las categorías temporales que nuestra consciencia cognoscitiva impone a cualquier dato percibido. "Quién fuese capaz de mantenerse en esa inocencia del inicio, preguntando como aquél niño ¿cómo se llama esto?, viendo el 'esto' antes de que el concepto lo enturbie, lo (...) vele" (Maillard, 2008: 32).

Pues bien, es esa experiencia temporal en el proceso de realización de un trabajo plástico la que constituyó el núcleo de investigación de los encuentros de California más arriba mencionados. 


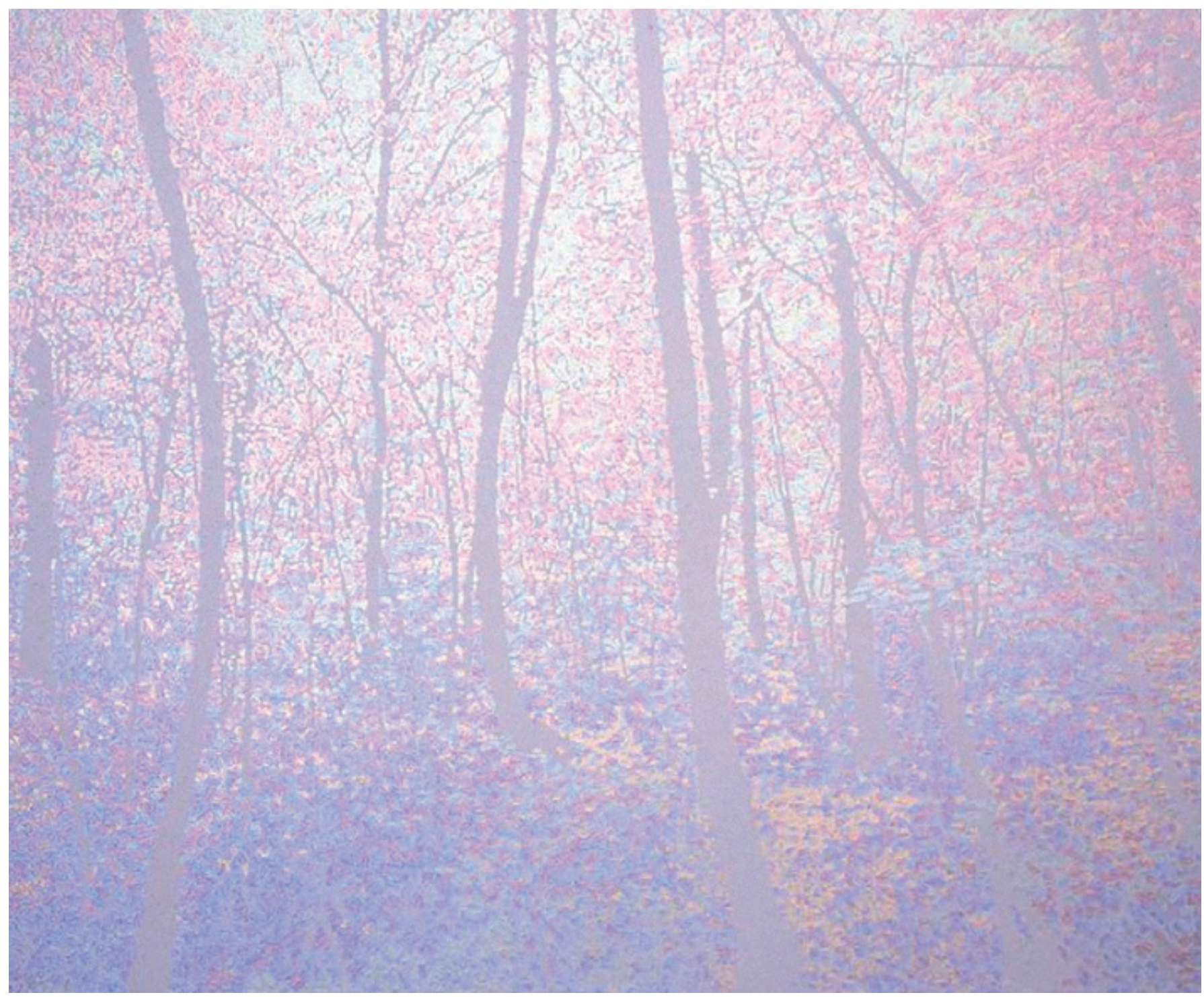

Fig. 3. Ohba Daisuke, Uroboros, 2008, 140 × 170 cm., 140 × 170 cm., acrílico sobre algodón.

\section{Recuperar la escucha}

A poco que hayamos visitado un taller de artesano, nos podremos haber dado cuenta de que en estos lugares se trabaja con un tempo que se separa tanto del ritmo de la actividad cotidiana como de los plazos que la tecnología y la producción industrial nos han impuesto. El tempo del artesano ni entiende de fragmentación ni acepta catalizador alguno. El sujeto que se enfrenta al telar $o$ al torno se involucra en unos ritmos que exigen de una actitud de escucha que se entrega a la infinitud del instante y que exige de un vaciamiento y una entrega cuya dinámica no es posible acelerar.

Frente al telar, el torno o cualquier instrumento al que se alíe, el artesano se embelesa frente a la materia que él trabaja porque sabe que, más allá de las características físicas o de la estructura formal que a esta define, también contiene un ritmo vital que la hace materia y que el artesano, conociéndolo, quiere hacer visible; un ritmo al que se entregará para seducirlo y convertirlo en el alma que a su pieza le dará fundamento, porque nada tiene que ver ese ritmo ni con la repetición de los gestos ni con las estructuras visibles, sino, más bien, con la discontinuidad y la variación.

El artesano sigue con atención su proceso porque sabe que la simple imitación automática, sin consciencia, no le permite el acceso a su más preciada búsqueda; porque conoce que el ritmo potencial de su trabajo solo se le hará visible a través de un proceso que le permita sentir más plenamente lo que está haciendo, a través de una superación de las exigencias técnicas que le consientan vivir con mayor profundidad cuanto mejor realice 


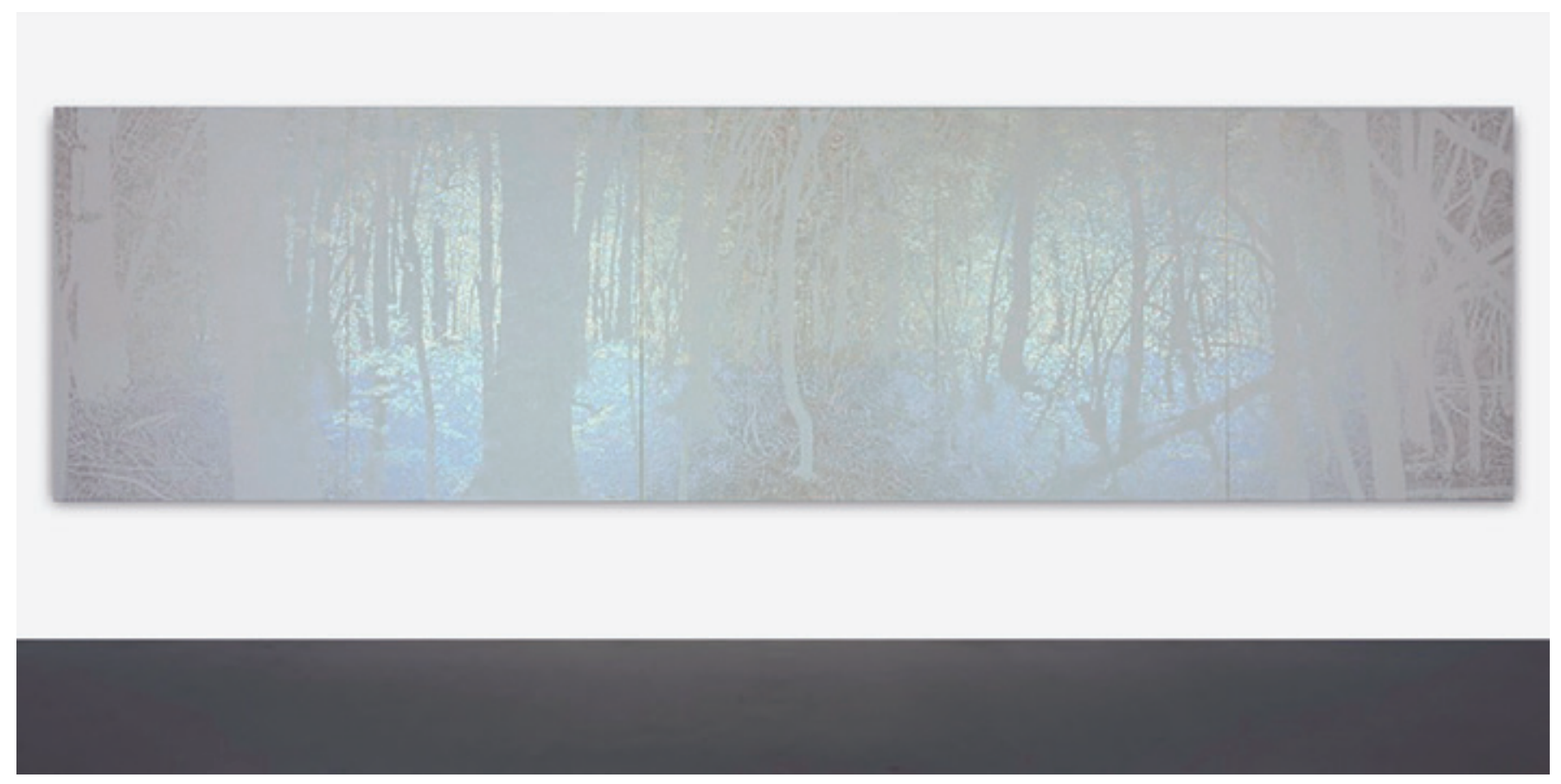

Fig. 4. Ohba Daisuke, Forest 1 (2009) 200 x 750 cm. (5 piezas), acrílico sobre algodón.

su trabajo. Y sabe que hacer un buen trabajo exige tener curiosidad, investigar y aprender de lo que, como en el río, va apareciendo en cada momento. Es artesano por el mero hecho de que se dedica a hacer bien su trabajo, por el simple hecho de hacerlo bien, sin grandes pretensiones y entregado a la lentitud de su tiempo, porque sabe que, en esa demora, en ese ritmo, es en el que él se hace, instante a instante, momento a momento, porque "es ese ritmo el que duerme y arrulla el alma" (Lasen, 1997: 191). No hay aquí lugar para hablar de significados porque estos nos alejan de la inmanencia de la materia que al artesano seduce, porque estos nos remiten a algún referente externo, a algo ajeno, a algo que trasciende e introduce ya una tensión práctica y una intervención de la voluntad y la intención que impide brotar el silencio que al ritmo hace visible. Es también Chantal Maillard la que nos dice que no existe el poeta, sino tan solo personas "que en ocasiones han sabido aquietarse lo suficiente" (Maillard, 2008: 34), personas que, solo silenciándose, han podido observar y trasmitir el ritmo de la vida a través del ritmo de sus creaciones.

En su libro El artesano, Richard Sennett plantea que no tiene ningún sentido que la historia haya trazado falsas líneas divisorias entre práctica y teoría, entre técnica y expresión, entre artesano y artista. Según el autor, la sociedad contemporánea debe acabar con esas distinciones para plantearse la cuestión de qué nos enseña de nosotros mismos el proceso de producir cosas concretas. "Pretendo rescatar al animal laborans del desprecio con el que lo trató Hannah Arendt" (Sennett, 2009: 38). Porque, según el autor, la distinción que Hannah Arendt realiza entre el animal laborans y el homo faber infravalora la capacidad de pensar de la persona práctica volcada en su trabajo ${ }^{4}$. Si para Arendt la mente entraba en funcionamiento cuando finalizaba el trabajo, a Sennet le parece más equilibrada su versión, según la cual en el proceso de producción están integrados el pensar y el sentir. Es más, no solo niega la inferioridad del hombre que hace, sino que llega a afirmar que es este animal laborans el verdadero guía del homo faber, porque el individuo aprende de sí mismo a través de las cosas que produce cuando no se encuentra sofocado por las ideas de eficacia y utilidad, ideas que durante toda la modernidad han destruido algo esencial a nuestra capacidad de pensar. Y en este sentido, es para él el artesano el modelo que nos enseña que el animal humano en el trabajo puede

\footnotetext{
4 Según Hannah Arendt, los seres humanos vivimos en dos dimensiones: la primera corresponde al animal laborans: hacemos las cosas, estamos absortos en una tarea y somos amorales; la segunda, al homo faber: un modo de vida superior en el que detenemos la producción y comenzamos a analizar y juzgar.
} 


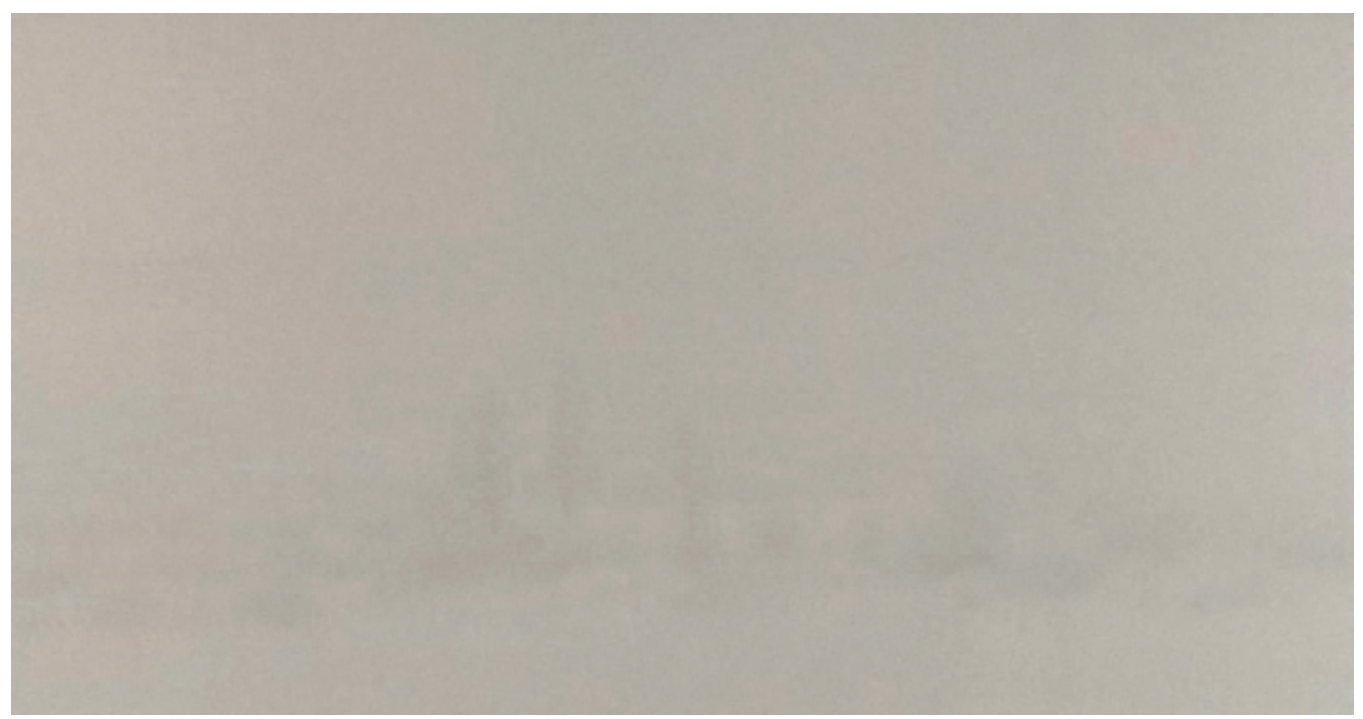

Fig. 5. Qiu Shishua, Sin título (2011), 150 × 286 cm., óleo sobre tela.

verse enriquecido por las habilidades y dignificado por el espíritu del proceso creativo que lleva a cabo ${ }^{5}$.

De este modo, se nos está invitando a mantener una relación de aprendizaje entre el trabajo a realizar y el sujeto que lo realiza, atendiendo y recuperando una actitud de escucha que supera la comprensión pragmática, funcional y significativa del proceso creativo; se nos está invitando a recuperar un tempo en el hacer que gira en torno a la idea de juego, un juego que se traza a través de la sedimentación de un hacer y un pensar que han precipitado con placer y lentamente. $Y$ es que en ese juego está el origen del diálogo que el artesano lleva a cabo con los materiales que él elige. Es esa actitud del niño que juega la que le permite al artesano establecer una relación amorosa con la materia y contactar con ella para dar forma a los ritmos que él quiere hacer visibles. Sin ese juego, sin esa escucha de lo que la materia es, no hay posible creación: sin la flexibilidad y el goce que el juego permite podrá haber construcción de imagen, de objeto, pero nunca revelación de los ritmos que toda aventura creativa debe perseguir.

Es la escucha la que le permite al artesano o al artista tener algo que decir, pero, ¿qué tipo de escucha es esa? Pues una escucha atenta que, modificando el tiempo, le permite al sujeto que la experimenta

$5 \quad$ No podemos caer en el error de pensar que la propuesta de Sennett es reaccionaria. En ningún momento el autor nos está invitando a abandonar la tecnología para volver a estructuras productivas previas al desarrollo tecnológico e industrial. De hecho, uno de los capítulos del libro lo dedica al análisis de Linux y la relación entre esta plataforma y lo que él entiende por modelo artesanal. sosegarse, aquietarse, para entregarse tan solo a aquello que está sucediendo, aquello que aún nada tiene que ver con el lenguaje y la codificación: su ritmo, su respiración, nuestro ritmo, nuestra respiración, el vacío, el silencio. "¿No será tiempo ahora de recuperar la escucha?" (Maillard, 2008: 34), pregunta la poeta.

Las obras de los artistas Qiu Shishua, Fu Xiaotong y Ohba Daisuke, arriba mencionados, están realizadas a través de una compleja elaboración que invita a vivir una relación especular entre el tempo del hacer y del observar. Si nos centramos en la obra del primero, observaremos que sus características formales y los complejos universos que crea invitan a una percepción desde códigos de variación y juego que invalidan cualquier previsión intelectual e incitan al abandono de los esquemas mentales reconocidos.

Como indica Max Wechsler en su texto The Image as an Epiphany: On the Paintings of Qiu Shihua, "las pinturas de Qiu Shihua mantienen una ambivalencia entre forma y no-forma, entre imagen y no-imagen. Son literalmente sensaciones más allá de la comprensión racional que se revelan únicamente en la contemplación de un vasto campo perceptivo que elude con persistencia toda comprensión conceptual" (Wechsler, 2010). Son obras que, recuperando la presencia física, hacen visible su ritmo y que, a través de la vuelta a la intensificación de la percepción, destruyen la continuidad simple del tiempo encadenado.

En todo poema verdadero se pueden encontrar los elementos de un tiempo detenido, de un tiempo que no sigue el compás, de un tiempo al que llamaremos 
vertical para distinguirlo de un tiempo común que corre horizontalmente con el agua del río y con el viento que pasa. (Bachelard, 2002: 94).

Las obras que Qiu Shihua está realizando desde los años 80 (Fig. 5) pretenden mantener al espectador en ese tiempo vertical que no sigue el compás, porque el compás es medida; ese tiempo que descubre el poeta, el artesano o el artista cuando recusa el tiempo horizontal o narrativo y se entrega a un ritmo sin pauta, discontinuo, dinámico y aleatorio frente al cual la voluntad se minimiza y repliega paulatinamente para dejar, finalmente, de intervenir. Porque si "la poesía sigue simplemente el tiempo de la vida, es menos que la vida; sólo puede ser más que la vida inmovilizando la vida, viviendo en el lugar de los hechos, la dialéctica, de las dichas y de las penas" (Bachelard, 2002: 93).

\section{Detener para tener}

Como Walter Benjamin sabía, "qué difícil puede ser encontrar palabras para lo que se tiene delante de los ojos". Porque, ¿cómo comprender el ritmo de una obra a través de un texto sin impedir que ese decir invada la calidad del encuentro con la misma? Si nos referimos a los trabajos de Qiu Shihua que aquí estamos revisando (Figs. 1 y 5), únicamente a través del contacto con la obra se puede vivir la experiencia que la justifica. Solo frente a su presencia es posible vivir con intensidad el ritmo que hace ser a la obra, un ritmo que no puede ser entendido a través de una reproducción porque ninguna simplificación puede absorber lo que ese ritmo tiene de propio. Y no es por una cuestión "aurática" o de "fetichización"; estamos ante un problema de equivalencias, ante la imposibilidad de una traducción: una reproducción reduce y banaliza la realidad de una pintura porque deja como residuo los ritmos que constituyen su propia esencia. Mediante el lenguaje y la teoría nos podemos acercar a la comprensión intelectual de la obra, pero nunca a esa excepcionalidad que las obras poseen. Cargados de argumentos no vamos a conseguir más que alejarnos de la experiencia singular del flujo en el que sus ritmos se desarrollan. Porque "el logos rompe el silencio de las cosas que carecen de lenguaje y luego fracasa al intentar expresar su ser inagotable en el concepto" (Safranski, 2009: 259).

Quizás en el ámbito de nuestra cultura esta defensa de la necesidad de reducir el discurso produce desasosiego. La consciencia de una experiencia singular que se deja ver o sentir, pero no comprender ni identificar, puede producir desazón, porque somos fruto y resultado de siglos de discurso y porque, además, no hemos articulado en todo este tiempo demasiados instrumentos que nos permitan abordar ese tipo de experiencia con el único apoyo del silencio. Hemos comprobado que nombrar, codificar y clasificar ayuda a ahuyentar los demonios que asaltan en ese silencio durante la experiencia de lo desconocido. “Detener para tener. Detener en el término (en el fin y en la palabra) lo que pertenece al curso, el estar-siendo de las cosas" (Maillard, 2008: 30), ha sido el fundamento de nuestro proceso de conocimiento. Hemos aprendido a pensar sobre aquello que nos inquieta con el fin de comprenderlo para clasificarlo y, así, neutralizar su efecto turbador. Porque, en realidad, lo que nos ha estimulado "no es tanto el ansia de saber o el gusto por el conocimiento como la necesidad de anular la distancia o desajuste que nos impide vivir reconciliados con el mundo" (De Ventós, 1998: 173). Y, quizá sin darnos cuenta, hemos aprendido que no hay mejor manera de protegerse ante un fenómeno que se escapa que introducirlo y reducirlo en el ámbito de lo inteligible. Creando esa distancia, habíamos llegado a creer que lo conocíamos y dominábamos, que habíamos conseguido superarlo llegando más allá; sin embargo, solo habíamos tapado ese desajuste con el ámbito de lo comprensible y, como consecuencia, nos habíamos alejado del territorio impreciso de las sensaciones y la experiencia. De ese territorio donde, como ya hemos visto, el ritmo se hace. "Nunca me pareció tan cierto que la razón sea el núcleo de un complejo sistema defensivo" (Maillard, 2008: 92). Quedémonos en el ver.

Pero, ¿a qué nos estamos refiriendo con la invitación a quedarse en el ver cuando sabemos que no podemos contar con un ojo inocente? Solo siendo conscientes en cada momento de las clasificaciones categóricas de nuestro discurso racional, solo cesando la desconfianza y la duda que el proceso de conocimiento impone a la realidad y la altera podremos llegar a comprender cuál es la naturaleza de ese ver al que nos estamos refiriendo.

El acto de ver no es el acto de una máquina de percibir lo real en tanto que compuesto por evidencias tautológicas (...) Dar a ver es siempre inquietar el ver, en su acto, en su sujeto. Ver es siempre una operación de sujeto, por lo tanto una operación hendida, inquieta, abierta (Didi-Huberman, 2006: 47).

Y ¿cuál es la razón para querer permanecer ante aquello que tan solo contamos como sospecha? ¿Por qué renunciar a lo inteligible para quedarnos frente a lo 
ignoto, a lo ausente, a lo que aún no es? Como artista llevo años trabajando con este problema, años intentando comprender lo que ocurre cuando el discurso se silencia, porque desde mi experiencia he podido constatar que "no nos sentimos en casa en el mundo interpretado" (Rilke, 2000: 101). Hace tiempo que soy consciente de la existencia de un nivel de realidad que he elaborado a través de imágenes porque no he sido capaz de transmitir a través del lenguaje sin arrancarle su esencia. Un tiempo en el que he cultivado una consciencia de una realidad intensa que me ha ayudado a comprender que "una identificación del yo con el lenguaje o la cultura es una insoportable reducción y violación del mismo" (De Ventós, 1998: 173).

Y no me refiero a la existencia de ningún ente sobrenatural o fantasmagórico; simplemente me refiero a la situación que aparece cuando se establece una perspectiva desde la que se puede mirar la distancia existente entre lo sabido y lo percibido, entre la memoria y el acontecimiento. A una distancia que no es más que el ejercicio de dejar que las cosas se aproximen y muevan hacia nosotros, a una capacidad de mostrar sin explicar y de describir sin definir. A esa actitud que hemos ido identificando en aquel sujeto que sabe "que no es razón, ni ser, ni unidad, ni verdad" (Zambrano, 1996: 25). A ese sujeto que ha sido capaz de tomar esa necesaria distancia que le ha permitido constatar que siempre nace algo a partir de ese punto al que nuestra razón es capaz de llevarnos, que siempre existe una realidad que comienza a manifestarse en el mismo límite en el que nuestro conocimiento se extingue. $Y$ de nuevo nos ayuda a comprenderlo el poeta cuando María Zambrano nos dice que él no se queda en "la cosa conceptual del pensamiento sino que aborda la cosa complejísima y real, la cosa fantasmagórica y soñada, la inventada, la que hubo y la que no habrá jamás" (Zambrano, 1996: 22). Solo en ese momento en el que el sujeto se expone, desde su consciencia convertida en distancia, desprovisto de cualquier instrumento intelectual y frente a un mundo abierto del que no tiene certeza alguna, se puede empezar a sondear ese ritmo que ha movilizado todo nuestro esfuerzo; solo bajo esas condiciones podremos entender lo que el ritmo de una obra nos está diciendo.

Pero también es el momento en el que se desencadena el vértigo al sentir la soledad y la fragilidad del vivir sin protección alguna para entregarse al espacio de la incertidumbre; el momento de sentir la angustia al saber que nuestra mirada se ha vaciado de esas visiones completas que nos habían permitido mantener una cierta lucidez; el momento de las debilidades y la melancolía; el momento de llegar a pensar que "la razón es la esperanza. Pero a costa de cuánta renuncia (...). La poesía se aferra al instante y no admite la esperanza y el consuelo de la razón" (Zambrano, 1989: 34).

\section{A modo de conclusión}

Esta es la experiencia íntima que nos interesa y que más arriba habíamos localizado en las obras de los artistas que planteábamos en nuestro punto de partida. Esa posibilidad del ver que Qiu Shihua nos ofrece por la que el sujeto se siente frente a un paradójico desasimiento que lo religa de nuevo al mundo: un desarraigo o desajuste con el objeto que produce esa determinada consciencia, ese género de consciencia que nos mostraba el poeta y andábamos buscando. Es entonces cuando la obra nace ya como un sedimento obrado por el tiempo, como el resultado de una mirada intensa y desprendida que se precipita dando lugar a un acontecimiento visual singular del que no nos interesa su pasado ni futuro. Nuestro contacto con esta no exige de historia: se reduce a un frágil vínculo que se desvanece en cada instante para volver a reaparecer si nuestra actitud sigue siendo de escucha, dándose cuenta de que "lo que no está allí es más importante que lo que está" (Reinhardt, cfr. Didi-Huberman, 2006: 161).

No es posible que la experiencia del ver se convierta en un acontecimiento subjetivo si la obra no suscita la aparición de una anomalía, si sus ritmos no conducen al espectador a otro lugar en el que no le sea fácil reconocerse. La obra siempre tiene que suscitar la "aparición de una lejanía por más cercana que pueda estar" (Benjamin, 2003: 47), una lejanía que, desde la distancia, se muestra para estar presente, para darse a conocer sin importar su distanciamiento, una lejanía donde perderse y desorientarse para percibir su ritmo. Solo ante esa situación de extrañeza y desorientación podrá tener lugar la experiencia personal que buscamos, "puesto que nuestra desorientación de la mirada implica al mismo tiempo ser desgarrados del otro y de nosotros mismos, en nosotros mismos" (Didi-Huberman, 2006: 161).

La obra se abre para mostrarnos de su mano su ritmo constante y escurridizo, para crearnos un espacio donde vivir nuestra pérdida. Forzados por la anomalía, hemos dado un salto desde lo que veíamos porque conocíamos, a lo que vemos que se nos escapa. $Y$ gracias a ese desajuste hemos podido "reconocer nuestra figura sobre un fondo que nos rebasa, al recorrer 
nuestro perímetro y explorar nuestras fronteras" (De Ventós, 1998: 173). Este es el fundamento de la obra: crear espacios donde reconocerse desde la pérdida, generar lugares de alta densidad desorientadora, presentar campos visuales en los que lo perceptible desemboca en lo irremediable, proponer territorios donde sentir la anomalía; en definitiva, construir imágenes inabordables para abrir un mundo, para mantenerse en el ritmo abierto de lo existente.

Todo depende de nuestro ver y de la posibilidad que al ver le concedamos. Porque la obra no es un lugar de paso hacia ningún otro sitio. La obra es un umbral interminable, un umbral absoluto en el que entregarse sin reservas al devenir del tiempo para vivir cada momento de la experiencia; porque "en el umbral mismo del vacío que crea la belleza, el ser (...) se rinde, rinde su pretensión de ser separado y aún la de ser él, él mismo; entrega sus sentidos que se hacen unos con el alma" (Zambrano, 1989: 286).

\section{Referencias}

Bachelard, Gaston (2002). La intuición del instante (1987). México: Fondo de Cultura Económica.

Benjamín, Walter (2003). La obra de arte en la época de su reproductibilidad técnica. México: Ítaca.

Didi-Huberman, Georges (2006). Lo que vemos, lo que nos mira (1997). Buenos Aires: Manantial.

Lasen, Amparo (1997). “Ritmos sociales y arritmia de la modernidad". Madrid: Política y Sociedad, n. 25.

Maillard, Chantal (2008). En la traza. Pequeña zoología poemática. Barcelona: Centro de Cultura Contemporánea de Barcelona.

(2010). Filosofía en los días críticos (2001).

Valencia: Pre-textos.

Rilke, Rainer María (2000). Elegías de Duino, Los Sonetos a Orfeo y otros poemas. Barcelona: Círculo de lectores.

Rubert de ventós, Xavier (1998). Crítica de la modernidad. Barcelona: Anagrama.

Safranski, Rüdiger (2009). Romanticismo. Barcelona:

Tusquets Editores.
Sennett, Richard (2010). El artesano (2009). Barcelona: Editorial Anagrama.

(1996). María, Filosofía y Poesía (1939). México: Fondo de Cultura Económica.

Wechsler, Max (2010). Qiu Shihua: The Image as an

Epiphany. Lucerna: Galerie Urs Maile.

Zambrano, María (1989). Algunos lugares de la pintura. Madrid: Espasa Calpe. 